\title{
Factors Influencing the Intention to Continue using B2B e-Commerce in Manufacturing SMEs
}

\author{
Lubna A. Hussein \\ School of Distance Education \\ Universiti Sains Malaysia \\ Penang, Malaysia \\ lubnafatlawi@gmail.com \\ Shaian Kiumarsi \\ Graduate School of Business \\ Universiti Sains Malaysia \\ Penang, Malaysia \\ kiumarsi78@gmail.com
}

\author{
Ahmad Suhaimi Baharudin \\ School of Computer Sciences \\ Universiti Sains Malaysia \\ Penang, Malaysia \\ asuhaimi@usm.my \\ Mohd Faiz Hilmi \\ School of Distance Education \\ Universiti Sains Malaysia \\ Penang, Malaysia \\ faiz@usm.my
}

\begin{abstract}
Business-to-Business (B2B) electronic commerce plays a tremendous role in nurturing the growth of Small and Medium Enterprises (SMEs) in developed and developing countries. However, the growth of B2B e-commerce in developing nations remains at the early adoption stage. The purpose of this paper is to examine the factors that influence B2B e-commerce adoption in SMEs in a developing country. The current study employs the questionnaire survey technique to gather information from 245 manufacturing SMEs in Jordan. It uses Structural Equation Modeling (SEM) to investigate the different factors that affect the intention to adopt or continue using B2B e-commerce. The study reveals that compatibility and outsourcing IT support have significant effects on the intention to continue using B2B ecommerce in Jordanian manufacturing SMEs. The implications of the findings are discussed.
\end{abstract}

Keywords-TOE framework; intention to continue using B2B ecommerce; outsourcing IT support

\section{INTRODUCTION}

Business-to-Business (B2B) electronic commerce is defined as the internet-enabled technologies which allow businesses to buy and promote products and offerings electronically and share value chain facts $[1,2]$. E-commerce gains attention as it helps in achieving better prices, improved quality, and customer satisfaction with lower costs. This attention is growing as more facilities are introduced in the field [3]. Furthermore, communication within the business has become faster and managing has become more efficient with the implementation of e-commerce technology [4]. Several studies have anticipated that $\mathrm{B} 2 \mathrm{~B}$ e-commerce will dominate the global economic system since it is considered as a significant determinant of the future increase of the economy [5]. Hence, developed countries have aggressively implemented B2B ecommerce, where it has become an essential part of business activities [6]. SMEs play an invaluable role in national and global economy [7].
The SMEs in Jordan play a vital role in boosting Jordan's economy through the provision of employment opportunities which account for $97 \%$ of all jobs. In Jordan SMEs contain $98.5 \%$ from the aggregate sum of enlisted enterprises and $60 \%$ of formal occupations [8]. It has been asserted that the use of B2B e-commerce is critical to the establishment of an organization as well as the future exponential growth of a nation [9]. Nevertheless, the B2B ecommerce expansion in the country is low, and some companies have stopped using B2B ecommerce for their businesses. Several B2B e-commerce adoption studies in SMEs have been undertaken in developing countries as can be represented by [5, 10-12]. A key area of concern in the previous studies is the lack of detail on how B2B e-commerce adoption by SMEs is undertaken as most researchers have used exploratory research methods such as surveys that lack depth and theoretical foundation [13]. According to $[5,10,13]$, organizations adopting $\mathrm{B} 2 \mathrm{~B}$ ecommerce in developing countries face challenges such as lack of IT infrastructure, lack of qualified staff to develop and support B2B e-commerce sites, lack of stuff skills and, low bank account and credit card penetration. However, lack of technical knowledge is considered as one of the major barriers confronting the use of B2B e-commerce in developing countries $[13,14]$. Therefore, it is necessary for the SMEs to train their staff on B2B e-commerce technology. But this training requires a lot of effort, time and financial resources, hence the SMEs take an alternative action of outsourcing IT support. Therefore, this study examines the main factors that affect B2B e-commerce continuance in manufacturing SMEs in Jordan.

\section{CONCEPTUAL RESEARCH MODEL}

The Technological, Organizational and Environmental (TOE) framework can be combined with Diffusion of Innovation (DOI) theory in a way that the five factors of DOI theory (relative advantage, compatibility, complexity, trialability, observability) are used in a technological context to 
describe the way that the adoption depends on the technologies inside and outside the enterprises. TOE has been used in studies related to B2B e-commerce adoption in business. For instance, the TOE framework has been used to identify factors influencing B2B e-commerce adoption of 320 Iranian manufacturing companies [11] and of 926 Vietnamese SMEs [15]. The TOE framework emphasizes the internal and external characteristics of a company. Internal characteristics refer to the organizational context in the TOE framework, whereas the external characteristics of the organization refer to the environmental context within the TOE framework. The TOE framework has been suggested as a useful starting point in studying B2B e-commerce adoption [2]. B2B e-commerce expansion in the Jordan can be considered as low, some firms may have even discontinued using B2B e-commerce for their business. The main reasons are uncertainties regarding online payments, information intensity for the products and lack of IT staff, because the majority of SMEs employ from 1 to 9 employees. The proposed research model depicted in Figure 1 shows the important variables that affect B2B e-commerce in Jordanian manufacturing SMEs. The technological context for this study refers to compatibility, organizational context (information intensity), and environmental context (outsourcing IT support and security) that influence the dependent variable (intention to continue using $\mathrm{B} 2 \mathrm{~B}$ e-commerce) which is the main contribution of this study since the previous B2B ecommerce technology models do not address the issue of intention to continue using $\mathrm{B} 2 \mathrm{~B}$ e-commerce. Therefore, the model in this study is to determine the factors that influence the intention to continue using B2B ecommerce.

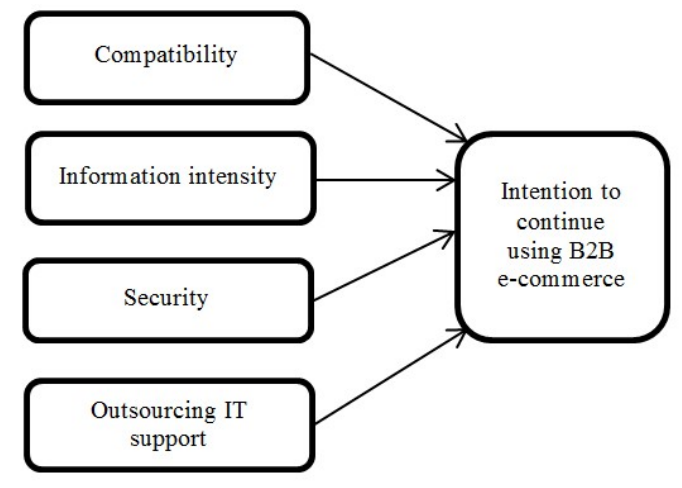

Fig. 1. Conceptual framework

\section{HYPOTHESIS DEVELOPMENT}

\section{$A$. Intention to Continue using B2B e-Commerce}

The intention to continue using B2B e-commerce is considered as the enterprise's intention to frequently use or proceed to the use of $\mathrm{B} 2 \mathrm{~B}$ e-commerce in the enterprise's current and future practices [16, 17].

\section{B. Compatibility}

Compatibility is defined as the consistent between B2B ecommerce and the organization existent values, preferred work practices and the way its suppliers and customers do their business [18]. The compatibility of B2B e-commerce to a company's current system is very important. Otherwise, it is very difficult to continue using $\mathrm{B} 2 \mathrm{~B}$ e-commerce since it may necessitate making major changes in the organization. The changes could lead to many difficulties that prevent its continuance. The use of $\mathrm{B} 2 \mathrm{~B}$ e-commerce requires considerable modifications to an organization's work practices, structure, processes and routines [6], therefore the perceived compatibility of the SMEs towards e-commerce is considered as a significant factor in B2B e-commerce adoption [19]. This is fundamental because the adoption may not succeed if the prevailing infrastructures are not consistent with the B2B ecommerce technology. Therefore, this study proposes that compatibility has a direct influence on the intention to continue using B2B e-commerce in manufacturing SMEs in Jordan.:

H1: Compatibility has a positive impact on the intention to continue using B2B e-commerce.

\section{Information Intensity}

Information intensity is defined as the complexity of the records required to understand the products or the services provided by an enterprise and the process of ordering them [20, 21]. Many enterprises are unable to continue using B2B ecommerce because their products or services require lengthy explanations which seem complicated, and the information for their products are difficult to explain. Information intensity may also be related to the enterprise's reliance on gaining access to up-to-date, reliable, applicable and accurate information whenever they want it. The Jordanian manufacturing SMEs have different information processing needs, and those SMEs with more information intensity are more likely to continue using B2B e-commerce. Therefore, this study proposes that information intensity has a positive impact on the intention to continue using B2B e-commerce by Jordanian manufacturing SMEs.

H2: Information intensity has a positive impact on the intention to continue using B2B e-commerce.

\section{Security}

Security is defined as the trust or confidence of the organization in using B2B e-commerce [13], hence it is a critical barrier to technology adoption. In Malaysia for instance, IT security is one of the fundamental factors that determine the adoption of B2B e-commerce [22]. Besides, the fear of fraud discourages many organizations in Jordan from making payments online. Moreover, various factors have been identified to contribute to the slow development of e-commerce in Arabic countries (including Jordan). The crucial role of security in technology adoption has been indicated in [23, 24]. Since Jordanian SMEs have concerns about security, a more secure $\mathrm{B} 2 \mathrm{~B}$ e-commerce would encourage the continuation of using $\mathrm{B} 2 \mathrm{~B}$ e-commerce. Thus, this study proposes that security has an effect on the intention to continue using B2B ecommerce in Jordanian SMEs.

H3: Security has a positive impact on the intention to continue using B2B e-commerce.

\section{E. Outsourcing IT support}

Outsourcing IT support is defined as the availability and the effectiveness of the support from external sources with respect to the implementation and maintenance of B2B e-commerce 
[5]. Outsourcing IT support is an important factor in IT adoption as it can facilitate the adoption, implementation, and on-going success [25], probably because many enterprises are confronted with a shortage of internal IT skilled personnel and difficulty in engaging external experts or consultants, hence the organizations can overcome the challenge via the development of their internal end-users' computing skills or get assistance from external sources. Therefore, this study proposes that outsourcing IT support influences the intention to continue using B2B e-commerce in the Jordanian SMEs.

H4: Outsourcing IT supports has a positive impact on the intention to continue using B2B e-commerce.

\section{Methodology}

\section{A. Measurement Development}

This study employs a quantitative survey, with a structured questionnaire, consisting of 22 items and divided into two sections, containing respondents' basic information and organization information. Besides basic information, the other items were measured using a seven-point Likert scale ranging from 'strongly disagree' to 'strongly agree'. The items capturing the theoretical constructs were developed in line with an extensive literature review.

\section{B. Data Collection}

The population of this study consists of the manufacturing SMEs in Amman, the capital city of Jordan. This study requires the respondents to possess certain knowledge of information technology [11] as well as general organizational infrastructure. The respondents are made up of department managers, assistant managers, executives and supervisors. The sample frame of this study consists of the manufacturing SMEs in the Amman Chamber of Industry, which is the association of manufacturing SMEs in the Hashemite Kingdom of Jordan. However, some studies have indicated that a sample size of 200 to 500 is adequate for multivariate data analysis [26], while other researchers asserted that a sample size large than 30 and less than 500 is appropriate for most researches [27].

\section{Analysis}

This study employs the Partial Least Squares (PLS) approach to determine the relationship between constructs using Smart PLS 3.0. The collected data were analyzed with SEM, based on the PLS approach. This method shows the relationships and the quality of connections among the factors in the proposed model. It uses the two-step technique [28] for data analysis. The first step consists of analyzing the model's measurements while the second step examines the structural relationships that exist among the latent constructs. Fundamentally, the two-step technique seeks to ascertain the measures' reliability and validity prior to the assessment of the model's structural relationships.

\section{RESUlTS}

\section{A. Demographic Variables}

The result for demographic variables is analyzed by using the SPSS Version 22, as shown in Table I. The data are collected through distributed questionnaires to the respondents in Manufacturing SMEs. A total number of 245 usable questionnaires were obtained from SMEs that have email or website and who intend to advance the level of utilization of B2B e-commerce technology.

TABLE I. DESCRIPTIVE INFORMATION

\begin{tabular}{|c|c|c|c|}
\hline Variable & Description & Number & $\%$ \\
\hline \multirow{3}{*}{$\begin{array}{l}\text { Number of } \\
\text { employees }\end{array}$} & $1-9$ & 147 & 60 \\
\hline & $10-49$ & 82 & 33.5 \\
\hline & $50-249$ & 16 & 6.5 \\
\hline \multirow{4}{*}{ Years of operation } & Less than 1 year & 6 & 2.4 \\
\hline & 1 year to less than 5 years & 77 & 31.4 \\
\hline & 5 years to less than 10 years & 73 & 29.8 \\
\hline & 10 or above & 89 & 36.3 \\
\hline \multirow{9}{*}{$\begin{array}{l}\text { Industry type } \\
\text { (manufacturing) }\end{array}$} & Therapeutic \& medical & 34 & 13.9 \\
\hline & Chemical \& cosmetics & 39 & 15.9 \\
\hline & Plastic \& rubber products & 14 & 5.7 \\
\hline & Engineering \& electronics & 34 & 13.9 \\
\hline & Furniture, Kitchens \& doors & 32 & 13.1 \\
\hline & $\begin{array}{c}\text { Paper, stationeries \& office } \\
\text { supplies }\end{array}$ & 13 & 5.3 \\
\hline & Food \& supply & 49 & 20.0 \\
\hline & Leather \& garments & 21 & 8.6 \\
\hline & Other & 9 & 3.7 \\
\hline \multirow[b]{2}{*}{ Capital } & Less than USD 42,440 & 80 & 32.7 \\
\hline & $\begin{array}{l}\text { Equal or more than USD } \\
\qquad 42,440\end{array}$ & 165 & 67.3 \\
\hline \multirow{5}{*}{$\begin{array}{l}\text { Level of B2B e- } \\
\text { commerce }\end{array}$} & Email with no website & 111 & 45.3 \\
\hline & $\begin{array}{c}\text { Website with communication } \\
\text { between supplier and } \\
\text { customers }\end{array}$ & 52 & 21.2 \\
\hline & $\begin{array}{c}\text { Website with just information } \\
\text { about products }\end{array}$ & 57 & 23.3 \\
\hline & Website with ordering online & 16 & 6.5 \\
\hline & $\begin{array}{l}\text { Website with online payment } \\
\text { and online transactions }\end{array}$ & 9 & 3.7 \\
\hline
\end{tabular}

\section{B. Assessment of Measurement Model}

The measurement model evaluated the reliability and validity of the constructs (variables). Composite reliability (CR) and Average Variance Extracted (AVE) were determined in the course of such evaluation [29]. For CR the recommended minimum threshold is 0.7 [30]. In this study, the CR values ranged from 0.874 to 0.958 which goes higher than the minimum value. All constructs have an AVE above 0.5, which demonstrated a satisfactory degree of convergent validity as suggested in [31]. Table II and Figure 2 show all the values were above the suggested value points, thus confirming the accomplishment of convergent validity. Moreover, S3 and S4 were deleted due to AVE which is less than 0.5.

\section{Discriminant Validity of the Measurement Model}

The current technique for assessing discriminant validity is the Heterotrait-Monotrait (HTMT) ratio of correlations. According to [32] the Fornell-Larcker criterion and the examination of cross-loadings are the major methods to evaluate discriminant validity. However, the simulation study has showed that these techniques are not reliable in detecting the lack of discriminant validity in common research situations. Consequently the HTMT ratio of correlations was proposed as a new approach that has the functionality to assess discriminant validity in variance-based SEM. Previous studies [32] 
suggested construct thresholds of 0.85 [33] and 0.9 [34] for HTMT to confirm discriminant validity. Hence, this study uses the HTMT of 0.85 to set up discriminant validity. Table III, reports the results of the discriminant validity evaluation of the measurement model using HTMT.

TABLE II. MEASUREMENT MODEL ASSESSMENT

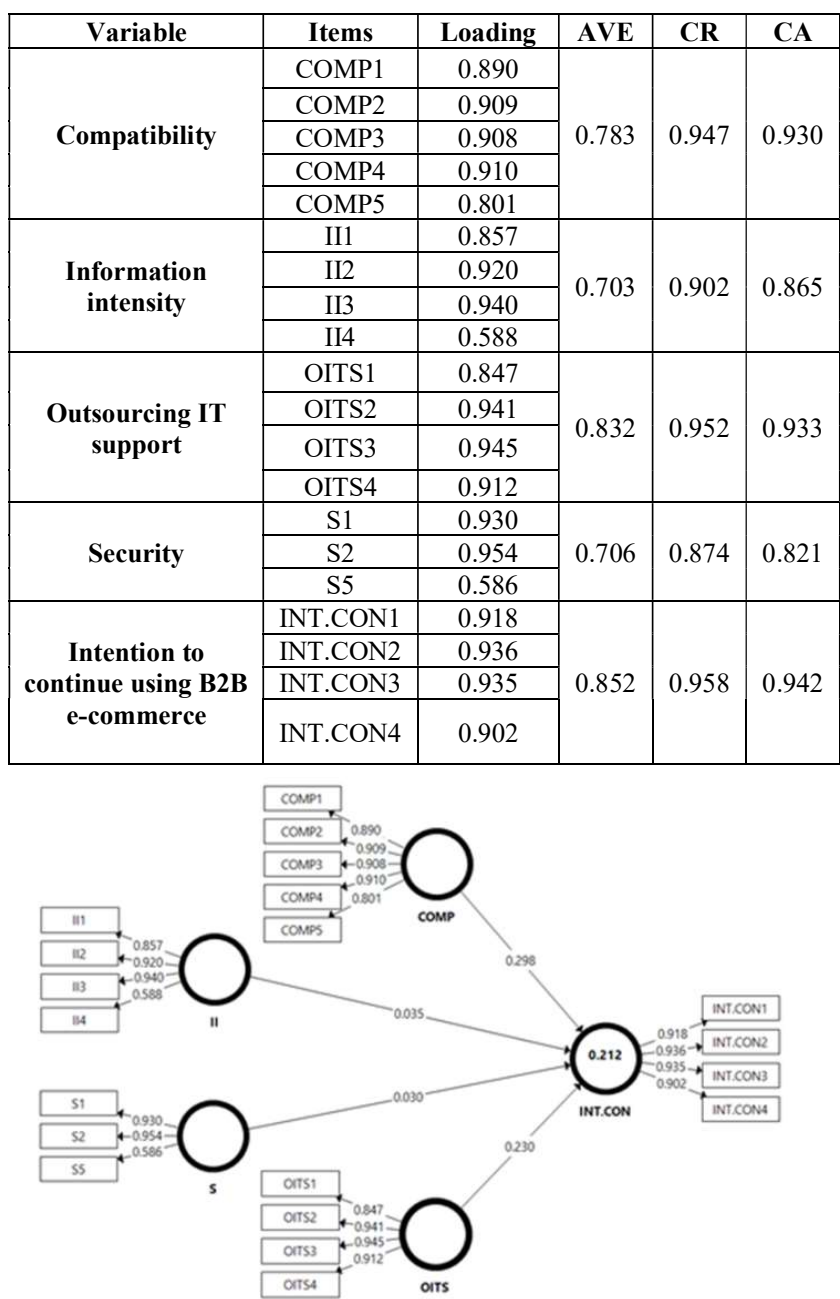

Fig. 2. Measurement model $(\mathrm{n}=245)$

TABLE III. DISCRIMINANT VALIDITY-HTMT

\begin{tabular}{|c|c|c|c|c|}
\hline COMP & II & INT.CON & OITS & S \\
\hline COMP & & & & \\
\hline II & 0.101 & & & \\
\hline INT.CON & 0.433 & 0.048 & & \\
\hline OITS & 0.459 & 0.065 & 0.373 & \\
\hline S & 0.290 & 0.168 & 0.154 & 0.161 \\
\hline
\end{tabular}

\section{Assessment of the Structural Model}

The path coefficient of the structural model and bootstrap analysis with 5,000 re-samples was used to check the structural model of the significance of path coefficients. The significant effects specified by the model were evaluated and the results indicated that the effects of COMP $\rightarrow$ INT.CON (H1) $(\beta=0.298, \mathrm{t}$-value $=4.445, \mathrm{p}<0.001)$, OITS $\rightarrow$ INT.CON $(\mathrm{H} 4)$ $(\beta=0.230, t-v a l u e=3.567, p<0.001)$ have positive relationship and are supported. Thus, $\mathrm{H} 1$ and $\mathrm{H} 4$ are supported. Table IV presents the significance of direct effects, the path coefficients, and the $\mathrm{f}^{2}$ values. According to [35], 0.02 signifies 'small' $\mathrm{f}^{2}$ effect, 0.15 signifies 'medium' effect, and more than 0.35 signifies 'large' effect. It could be noted that there is a small effect of dropping incentives from the model. Authors in [32] stressed the importance of presenting the Standardized Root Means Square Residual (SRMR) as an approximation of model fit. The recommended SRMR score of less than 0.08 is appropriate for a satisfactory PLS path models fit. This study's SRMR score of 0.058 suggesting a satisfactory model fit. Besides, the INT.CON's R-square value of 21.2 fulfilled the rule of thumb recommended by [30]. Figure 3 shows the path analysis of t-values results.

TABLE IV. RESULTS FROM HYPOTHESIS TESTING

\begin{tabular}{|c|c|c|c|c|c|c|}
\hline & $\begin{array}{c}\text { Beta } \\
\text { value }\end{array}$ & SE & t-value & p-value & Results & $\mathbf{f}^{2}$ \\
\hline H1 & 0.298 & 0.067 & 4.445 & 0.000 & Supported & 0.084 \\
\hline H2 & 0.035 & 0.068 & 0.523 & 0.300 & Not supported & 0.002 \\
\hline H3 & 0.030 & 0.056 & 0.542 & 0.294 & Not supported & 0.001 \\
\hline H4 & 0.230 & 0.064 & 3.567 & 0.000 & Supported & 0.054 \\
\hline
\end{tabular}

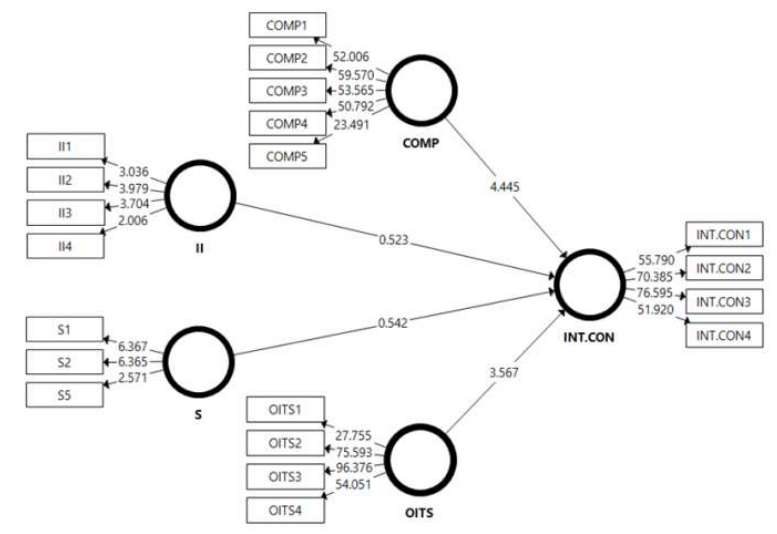

Fig. 3. PLS-path analysis of t-values $(n=245)$

\section{DISCUSSION}

The findings of this study are discussed with consideration of three distinct categories namely organization, technology and environment. From the perspective of technological factors, this study reveals that compatibility is a significant factor that influences the intention to continue using B2B ecommerce technology. Thus, the adoption of B2B e-commerce should be compatible with the prevailing system otherwise the adoption level is low and will have no effects. In the context of organizational factor, this study indicates that information intensity has no significant effect on the intention to continue using B2B e-commerce technology. The reason for this result is because most of the manufacturing SMEs in Jordan are at a lower level of B2B e-commerce adoption. Hence, it is possible that despite their high information intensity, they are already satisfied with the use of e-mail to disseminate information. In the environmental context, the study reveals that outsourcing IT support has a significant effect on the intention to continue using B2B e-commerce in the Jordanian manufacturing SMEs. Basically, outsourcing IT support includes support in the 
implementation of $\mathrm{B} 2 \mathrm{~B}$ applications and the use of the applications where the support is obtained from the sources outside the business organization [36]. Outsourcing IT support functions as an agent of change in B2B e-commerce adoption assisting enterprises that lack in IT infrastructure and knowledge necessary for $\mathrm{B} 2 \mathrm{~B}$ e-commerce adoption. In this study, the majority of the manufacturing SMEs have the 1-9 employees. Therefore, this small number makes the SMEs not to have much technical support internally. Having a limited number of employees with IT knowledge could inhibit the intention to continue using B2B e-commerce. So, they depend on outsourcing IT to help them to continue using B2B ecommerce technology. Regarding security, this study shows that security has no significant effect on the intention to continue using B2B e-commerce in the Jordanian manufacturing SMEs. This is consistent with the findings in [24] regarding security and its not significant effect on cloud computing adoption. For this study, since the majority of SMEs are at a low level of B2B e-commerce adoption without online transactions, there is no reason to be concerned about security.

\section{IMPLICATIONS OF THE STUDY}

\section{A. Implications for Agencies}

This study shows that the majority of the manufacturing SMEs in Jordan are enterprises with a small number of employees. Therefore, they lack the IT staff to implement B2B e-commerce technology. The findings serve as guidelines for government agencies and Non-Profit Organizations (e.g. Jordan Chamber of Industry, Amman Chamber of Industry, and JEDCO (Jordan Enterprise Development Corporation)) to evaluate the existing policies and design the strategy and plan to support B2B e-commerce technology in manufacturing SMEs in Jordan. They could assist the manufacturing SMEs to understand the usefulness of B2B e-commerce adoption or encourage them to continue using it. Ways should be provided to link SMEs and IT consultants available in the country. Such strategies would include holding courses and workshops by the local IT companies where the IT consultants can educate and train decision makers of the SMEs on B2B e-commerce usefulness through conferences, workshops and personal visits. They may also persuade and assist SMEs with a low level of B2B e-commerce technology adoption to implement a higher level of adoption. Another strategy is that they may encourage the IT providers to offer trial periods before full implementation of B2B e-commerce. Also, ways should be provided to link SMEs and IT consultants from abroad. Strategies may include advertising the availability of offshore and virtual IT consultants. Like the local IT support, policies may also involve the motivation for IT organizations and SMEs to link.

\section{B. Implications for IT Developers}

In high-level adoption of B2B e-commerce, the provision of online electronic payment is crucial to ensure that the business transactions with customers or suppliers are convenient and swift. But it is the responsibility of the firms to ensure the safety of the transactions and the confidentiality of the information disclosed during transactions.

\section{FUTURE WORK}

This study focused on the factors that influence the intention to continue using $\mathrm{B} 2 \mathrm{~B}$ e-commerce among the manufacturing SMEs with varying levels of B2B e-commerce adoption. Future studies could examine the factors that influence the intention to continue using B2B e-commerce at each level of B2B e-commerce adoption. This would provide complete insight into B2B e-commerce adoption by identifying the different factors associated with different $\mathrm{B} 2 \mathrm{~B}$ e-commerce adoption levels.

APPENDIX: QUASTIONNAIRE ITEMS

\begin{tabular}{|c|c|c|c|c|}
\hline No & Construct & & Items & References \\
\hline \multirow{5}{*}{1} & \multirow{5}{*}{ Compatibility } & Comp1 & B2B e-commerce is compatible with our existing values & \multirow{5}{*}[5,18]{} \\
\hline & & Comp2 & B2B e-commerce is compatible with our supplier's and customer's ways of doing business. & \\
\hline & & Comp3 & B2B e-commerce creates changes which are compatible with our current business operations. & \\
\hline & & Comp4 & B2B e-commerce is compatible with our preferred work practice. & \\
\hline & & Comp5 & B2B e-commerce is compatible with our organization's traditional operating procedures & \\
\hline \multirow{4}{*}{2} & \multirow{4}{*}{$\begin{array}{l}\text { Information } \\
\text { intensity }\end{array}$} & III & The product/services in our industry are complicated or complex to understand. & \multirow{4}{*}[20,21]{} \\
\hline & & III & The product/services in our industry generally require a lot of information before selling. & \\
\hline & & III3 & Ordering products in our industry by customers are generally a complex process. & \\
\hline & & III & Our firm is dependent on up-to-date information & \\
\hline \multirow{4}{*}{3} & \multirow{4}{*}{$\begin{array}{l}\text { Outsourcing } \\
\text { IT support }\end{array}$} & OITS1 & $\begin{array}{l}\text { There are businesses in the community who provide technical support for the executive use of B2B e- } \\
\text { commerce technology. }\end{array}$ & \multirow{4}{*}[5,38]{} \\
\hline & & OITS2 & There are agencies in the community who provide training sessions for adoption. & \\
\hline & & OITS3 & $\begin{array}{l}\text { Outsourcing IT support in the region are actively promoting B2B e-commerce technology and other } \\
\text { technologies by providing incentives for adoption. }\end{array}$ & \\
\hline & & OITS4 & We can easily obtain support from local IT support as we implement B2B e-commerce. & \\
\hline \multirow{5}{*}{4} & \multirow{5}{*}{ Security } & S1 & Our firm is concerned that the information involved in a transaction over the internet is not private. & \multirow{5}{*}[13,37]{} \\
\hline & & S2 & Our firm lacks confidence about the security of B2B e-commerce transactions. & \\
\hline & & S3 & Our firm trusts that the internet can protect the confidential data that we enter on the websites. & \\
\hline & & S4 & Our customers are worried about the security of the internet and will not use the internet to make payments & \\
\hline & & S5 & Our firm does not have confidence in the payment system of B2B e-commerce. & \\
\hline \multirow{4}{*}{5} & \multirow{4}{*}{\begin{tabular}{|c|} 
Intention to \\
continue using \\
B2B e- \\
commerce \\
\end{tabular}} & INT.CON1 & I intend to use B2B e-commerce in my organization frequently. & \multirow{4}{*}[16,17]{} \\
\hline & & INT.CON2 & I intend to continue using B2B e-commerce in my organization in the future. & \\
\hline & & NT.CON3 & I will always try to use B2B e-commerce in my organization daily. & \\
\hline & & INT.CON4 & I plan to continue to use B2B e-commerce frequently & \\
\hline
\end{tabular}




\section{REFERENCES}

[1] I. Sila, "The state of empirical research on the adoption and diffusion of business-to-business e-commerce", International Journal of Electronic Business, Vol. 12, No. 3, pp. 258-301, 2015

[2] L. A. Hussein, A. S. Baharudin, K. Jayaraman, S. Kiumarsi, "B2b ecommerce technology factors with mediating effect perceived usefulness in Jordanian manufacturing SMEs", Journal of Engineering Science and Technology, Vol. 14, No. 1, pp. 411-429, 2019

[3] L. A. Qaisi, A. Mesleh, A. A. Qaisi, A. Sharadqh, B. Zahran, J. Alkasassbeh, M. Olaimat, "Evaluation of e-commerce website functionality using a Mamdani fuzzy system", Engineering, Technology \& Applied Science Research, Vol. 5, No. 5, pp. 860-863, 2015

[4] D. Y. Govinnage, K. M. V. Sachitra, "Factors affecting e-commerce adoption of small and medium enterprises in Sri Lanka: Evidence from retail sector", Asian Journal of Advanced Research and Reports, Vol. 6, No. 2, pp. 1-10, 2019

[5] M. Ghobakhloo, D. A. Aranda, J. B. Amado, "Adoption of e-commerce applications in SMEs", Industrial Management and Data Systems, Vol. 111, No. 8, pp. 1238-1269, 2011

[6] A. Alsaad, R. Mohamad, N. A. Ismail, "The moderating role of trust in business to business electronic commerce (B2B EC) adoption", Computers in Human Behavior, Vol. 68, pp. 157-169, 2017

[7] L. A. Lopes, N. F. Melao, "Website content and design in SME: Insights from Portugal", International Journal of Electronic Business, Vol. 13, No. 1, pp.70-97, 2016

[8] K. A. M. A. Tamimi, M. S. Jaradat, "The role of small medium enterprises in reducing the problem of unemployment in Jordan", International Journal of Development and Economic Sustainability, Vol. 7, No. 2, pp. 28-36, 2019

[9] H. Hamad, L. Elbeltagi, H. E. Gohary, “An empirical investigation of business-to-business e-commerce adoption and its impact on SMEs competitive advantage: The case of Egyptian manufacturing SMEs", Strategic Change, Vol. 27, No. 3, pp. 209-229, 2018

[10] A. S. A. Somali, R. Gholami, B. Clegg, "Determinants of B2B ecommerce adoption in Saudi Arabian firms", International Journal of Digital Society, Vol. 2, No. 2, pp. 406-415, 2011

[11] M. Mohtaramzadeh, T. Ramayah, C. J. Hwa, "B2B e-commerce adoption in Iranian manufacturing companies: Analyzing the moderating role of organizational culture", International Journal of HumanComputer Interaction, Vol. 34, No. 7, pp. 621-639, 2017

[12] E. C. Ocloo, H. Xuhua, S. Akaba, M. Addai, D. W. Brown, A. S. Kwofie, "B2B e-commerce adoption amongst manufacturing SMEs: Evidence from Ghana", Australian Journal of Economics and Management Science, Vol. 8, No. 1, pp. 126-146, 2018

[13] A. K. Garg, T. Choeu, "The adoption of electronic commerce by small and medium enterprises in Pretoria East", The Electronic Journal of Information Systems in Developing Countries, Vol. 68, No. 1, pp. 1-23, 2015

[14] N. R. Vajjhala, S. G. Thandekkattu, "Potential and barriers to adoption of B2B e-commerce in SMEs in transition economies: Case of Albania", Management, Vol. 12, No. 2, pp. 155-169, 2017

[15] L. V. Huy, F. Rowe, D. Truex, M. Q. Huynh, "An empirical study of determinants of e-commerce adoption in SMEs in Vietnam an economy in transition", Journal of Global Information Management, Vol. 20, No. 3, pp. 1-35, 2012

[16] O. N. Omigie, H. Zo, J. J. Rho, "User acceptance of mobile broadband in Nigeria”, Information and Knowledge Management, Vol. 5, No. 7, pp. 62-78, 2015

[17] V. Venkatesh, J. Y. L. Thong, X. Xu, "Consumer acceptance and use of information technology: Extending the unified theory of acceptance and use of technology", MIS Quarterly, Vol. 36, No. 1, pp. 157-178, 2012

[18] M. G. R. Alam, A. K. M. Masum. L. S. Beh, C. S. Hong, "Critical factors influencing decision to adopt human resource information system (HRIS) in hospitals", Plos One, Vol. 11, No. 8, Article ID 0160366, 2016
[19] L. Daoud, M. Ibrahim, "Antecedents and impacts of electronic procurement usage among Jordanian large firms", Journal of Advanced Research in Business and Management Studies, Vol. 14, No. 1, pp. 5265,2019

[20] N. C. Osakwe, M. Chorancova, M. Agu, "Can micro-enterprises leverage on the adoption of corporate websites to bolster their brand visibility? Examining salient adoption issue in Nigeria", Information Development, Vol. 32, No. 4, pp. 904-919, 2016

[21] Y. S. Wang, H. T. Li, C. R. Li, D. Z. Zhang, "Factors affecting hotels' adoption of mobile reservation systems: A technology-organizationenvironment framework", Tourism Management, Vol. 53, pp. 163-172, 2016

[22] T. L. Sam, L. H. Eam, "Estimating the determinants of B2B e-commerce adoption among small \& medium enterprises", International Journal of Business and Society, Vol. 12, No. 1, pp. 15-30, 2011

[23] M. M. Alzubi., M. A. Alkhawlani, Y. A. B. E. Ebiary, "Investigating the factors affecting university students' e-commerce intention towards: A case study of Jordanian universities", Journal of Business and Retail Management Research, Vol. 12, No. 1, pp. 189-194, 2017

[24] T. Lynn, X. Liang, A. Gourinovitch,, J. P. Morrison, G. Fox, P. Rosati, "Understanding the determinants of cloud computing adoption for high performance computing", 51st Hawaii International Conference on System Sciences, Hawaii, USA, January 3-6, 2018

[25] W. Boonsiritomachai, G. M. McGrath, S. Burgess, "Exploring business intelligence and its depth of maturity in Thai SMEs", Cogent Business \& Management, Vol. 3, No. 1, pp. 1-17, 2016

[26] J. F. Hair, W. C. Black, B. J. Babin, R. E. Anderson, Multivariate data analysis, 7th Edition, Pearson, 2010

[27] U. Sekaran, R. Bougie, Research methods for business: A skill building approach, Wiley, 2016

[28] J. F. Hair, C. M. Ringle, M. Sarstedt, "PLS-SEM: Indeed a silver bullet", Journal of Marketing Theory and Practice, Vol. 19, No. 2, pp. 139-152, 2011

[29] J. F. Hair, G. T. M. Hult, C. M. Ringle, M. Sarstedt, A primer on Partial Least Squares Structural Equation Modeling (PLS-SEM), 2nd Edition, Sage, 2017

[30] J. F. Hair, M. Sarstedt, L. Hopkins, V. G. Kuppelwieser, "Partial Least Squares Structural Equation Modeling (PLS-SEM): An emerging tool in business research", European Business Review, Vol. 26, No. 2, pp. 106121,2014

[31] C. Fornell, D. F. Larcker, "Evaluating structural equation models with unobservable variables and measurement error", Journal of Marketing Research, Vol. 18, No. 1, pp. 39-50, 1981

[32] J. Henseler, C. M. Ringle, M. Sarstedt, "A new criterion for assessing discriminant validity in variance-based structural equation modelling", Journal of the Academy of Marketing Science, Vol. 43, pp. 115-135, 2015

[33] R. B. Kline, Principles and practice of structural equation modelling, The Guilford Press, 2015

[34] A. H. Gold, A. Malhotra, A. H. Segars, "Knowledge management: An organizational capabilities perspective", Journal of Management Information Systems, Vol. 18, No. 1, pp. 185-214, 2001

[35] J. Cohen, Statistical power analysis for the behavioral sciences, Routledge, 1988

[36] T. Ramayah, N. S. Ling, S. K. Taghizadeh, S. A. Rahman, "Factors influencing SMEs website continuance intention in Malaysia", Telematics and Informatics, Vol. 33, No. 1, pp. 150-164, 2016

[37] S. S. Alam, M. Y. Ali, M. F. M. Jani, "An empirical study of factors affecting electronic commerce adoption among SMEs in Malaysia", Journal of Business Economics and Management, Vol. 12, No. 2, pp. 375-399, 2011

[38] P. Ifinedo, "Facilitating the intention to expand e-business payment systems use in Nigerian small firms: An empirical analysis", in: EBusiness: Applications and Global Acceptance, IntechOpen, 2012 